Supporting Information for:

\title{
Formation of Bulky DNA Adducts by Non-Enzymatic Production of 1,2- Naphthoquinone-Epoxide from 1,2-Naphthoquinone under Physiological Conditions
}

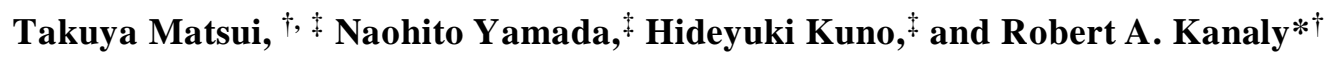

tDepartment of Life and Environmental System Science, Graduate School of Nanobiosciences, Yokohama City University, 22-2 Seto, Kanazawa, Yokohama, Kanagawa, 236-0027, Japan

${ }^{\sharp}$ Toxicology Research Laboratories, Central Pharmaceutical Research Institute Japan Tobacco Inc., 1-13-2

Fukuura, Kanagawa 236-0004, Japan

\section{Contents:}

Figure S1 Mass spectra acquired from product ion scan analyses for products III through IV, page S3.

Figure S2 CID fragmentation pathways of products II and III (A; N7, B; N1) and products IV and V (C; N2), page S4.

Figure S3 ${ }^{1} \mathrm{H}$ NMR spectrum for product IV, page S5.

Figure S4 ${ }^{1} \mathrm{H}$ NMR spectrum for product II, page S5.

Figure S5 Extracted ion chromatogram from full scan MS analysis of the reaction of isolated product I with dG under $\mathrm{pH} 7.4$ conditions. The peaks which corresponded to $[\mathrm{M}+\mathrm{H}]^{+}=442$ with retention times that were identical to products II through V were detected, page S6.

Figure S6 Results of LC/ESI(+)-MS/MS product ion scan analyses of (A) synthesized 1,2-NQepoxide and (B) product I produced during the reaction of 1,2-NQ with $\mathrm{dG}$, Collision energy was 45V. Results were nearly identical, page S6.

Figure S7 Results of LC/ESI(+)-MS analyses of reaction mixtures of 1,2-NQ-epoxide with dG in phosphate buffer, pH 7.4, after 17 hours (A) UV (260 nm); (B) EIC, [M + H $]^{+}=442$, page S7.

Figure S8 Monitoring of 1,2-NQ-epoxide by peak area measurement (HPLC-UV $260 \mathrm{~nm}$ ) when (A) synthesized 1,2-NQ-epoxide (6.2 mM) was incubated directly in phosphate buffer with $\mathrm{dG}$ and (B) when 1,2-NQ (6.2 mM) was incubated in phosphate buffer with dG. Measurement of the total amount of products II through V as the sum of their 4 peak areas when (C) synthesized 1,2-NQ-epoxide was 
incubated directly in phosphate buffer with dG and (D) when 1,2-NQ was incubated in phosphate buffer with $\mathrm{dG}$ from the same experiments, page $\mathbf{S 7}$.

Figure S9 Results of LC/ESI(+)-MS/MS analyses of reaction products formed after addition of 1,2NQ to phosphate buffer, $\mathrm{pH} 7.4$, after 24 hours. (A) UV 260nm; (B) extracted ion chromatogram of $[\mathrm{M}+\mathrm{H}]+=175$ (1,2-NQ-epoxide, $8.5 \mathrm{~min}$; lawsone, $17.4 \mathrm{~min})$; (C) extracted ion chromatogram of $[\mathrm{M}+\mathrm{H}]+=317$; (D) extracted ion chromatogram of $[\mathrm{M}+\mathrm{H}]+=331$, page S8.

Figure S10 Results of LC/ESI(+)-MS/MS product ion scan analyses of (A) an authentic standard of 2-hydroxy-1,4-naphthoquinone and (B) the product detected at $[\mathrm{M}+\mathrm{H}]^{+}=175$ after 1,2-NQ was added to phosphate buffer, $\mathrm{pH} 7.4$, for 24 hours. Collision energy was $45 \mathrm{~V}$ for each analysis, page S8.

Figure S11 Results of LC/ESI(+)-MS/MS product ion scan analyses of high molar mass products detected during the reaction of 1,2-NQ in phosphate buffer, $\mathrm{pH} 7.4$, for 13 hours; (A) the spectrum of the product that corresponded to $[\mathrm{M}+\mathrm{H}]^{+}=317$; (B) the spectrum of the product that corresponded to $[\mathrm{M}+\mathrm{H}]^{+}=331$. Collision energy was $30 \mathrm{~V}$ for each analysis, page $\mathbf{S 9}$.

Figure S12 Results of LC/ESI(+)-MS/MS analyses of reaction products from reactions of 2hydroxy-1,4-NQ (lawsone) with dG at 0 hours (A) UV 260nm, (B) extracted ion chromatogram of [M $+\mathrm{H}]+=442$; and after 24 hours (C) UV260nm, (D) extracted ion chromatogram of $[\mathrm{M}+\mathrm{H}]+=442$, page $\mathrm{S10}$.

Figure S13 Results of LC/ESI(+)-MS/MS analyses of reaction products from reactions of 1,2-NQ with $\mathrm{dG}$ after 15 hours at $37{ }^{\circ} \mathrm{C}$, with DETAPAC, (A) UV260nm, (B) extracted ion chromatogram of $[\mathrm{M}+\mathrm{H}]+=442$; without DETAPAC, (C) UV 260nm, (D) extracted ion chromatogram of $[\mathrm{M}+\mathrm{H}]+=$ 442, page $\mathbf{S 1 1 .}$

Figure S14 Relative amounts of products II through V (sum of 4 peaks) and product I detected under Ar gas atmosphere conditions and under ambient air conditions when 1,2-NQ was reacted with $\mathrm{dG}$ in phosphate buffer, $\mathrm{pH} 7.4$, for 8 hours in the dark, page S12. 

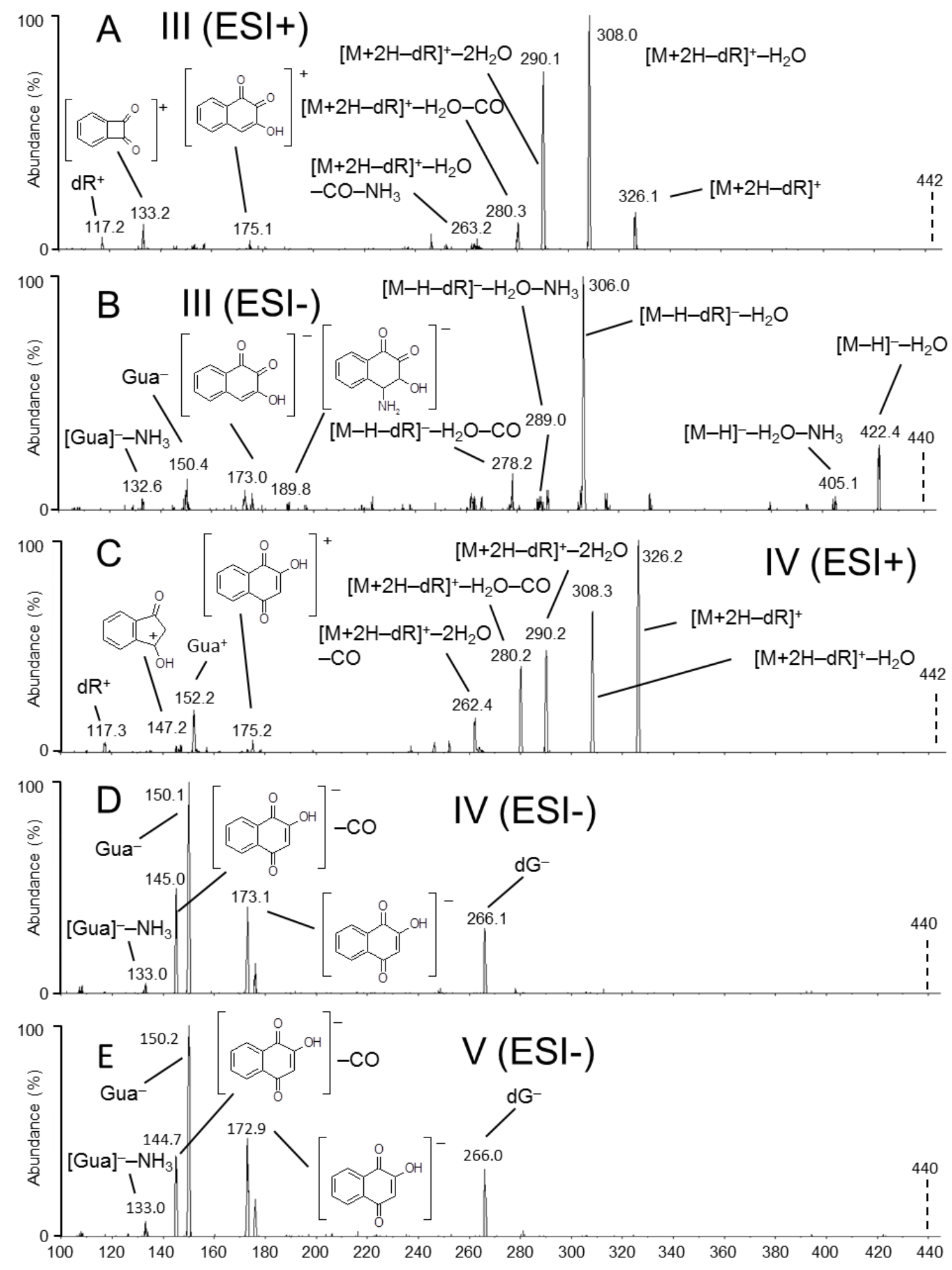

Figure S1 Mass spectra acquired from product ion scan analyses for products III through IV. 

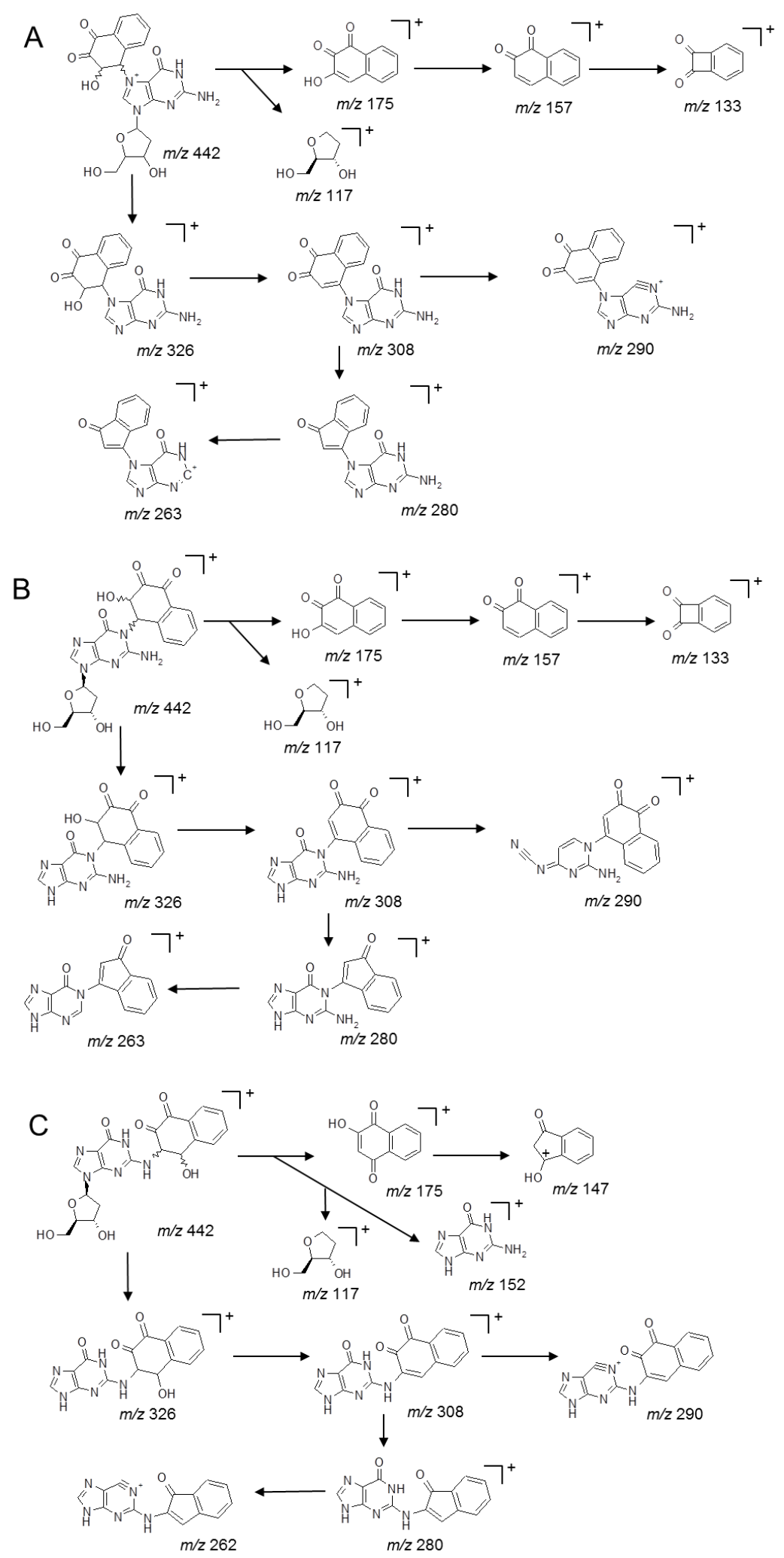

Figure S2 CID fragmentation pathways of products II and III (A; N7, B; N1) and products IV and $\mathrm{V}(\mathrm{C} ; \mathrm{N} 2)$. 


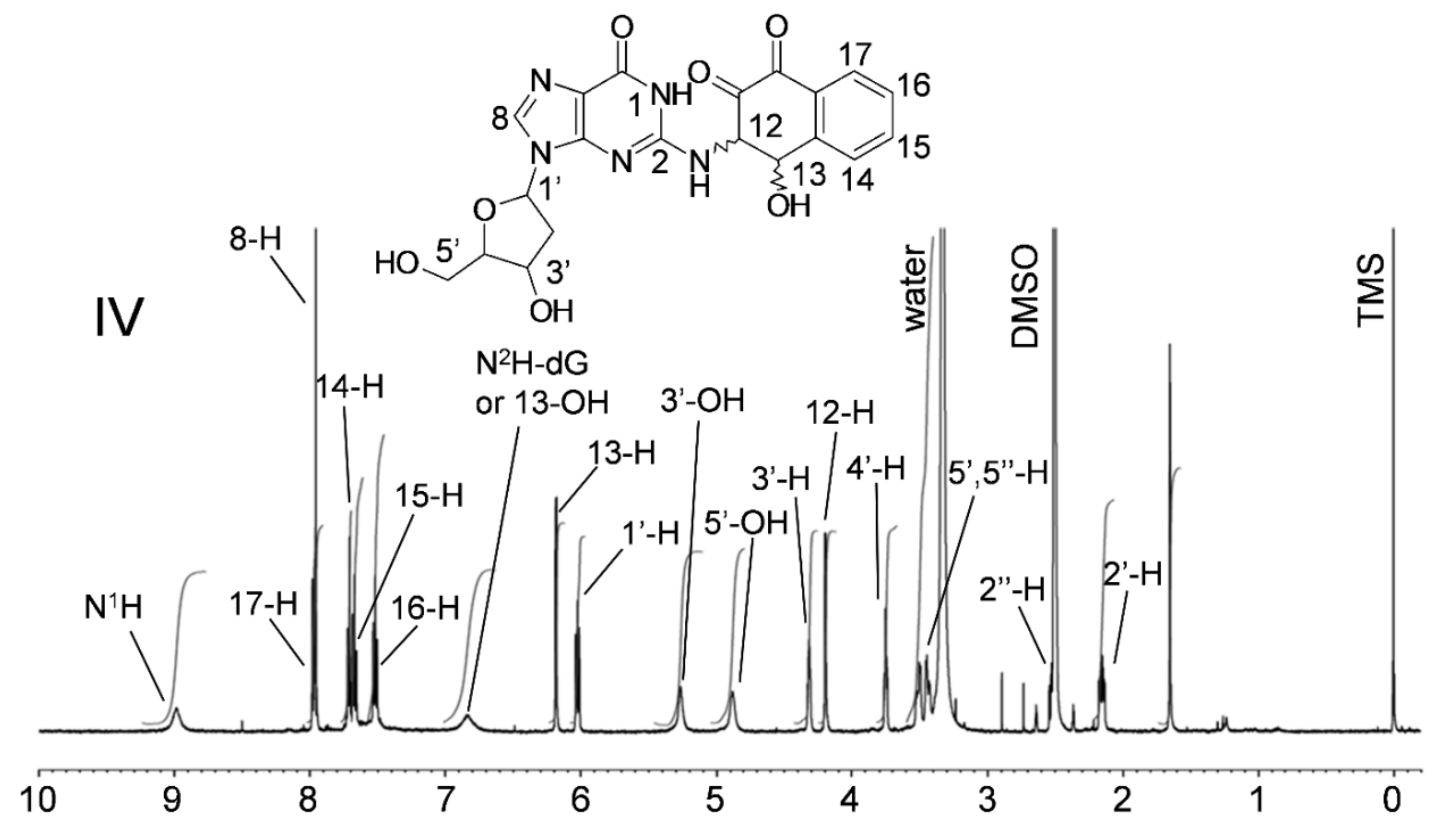

Figure S3 ${ }^{1} \mathrm{H}$ NMR spectrum for product IV.

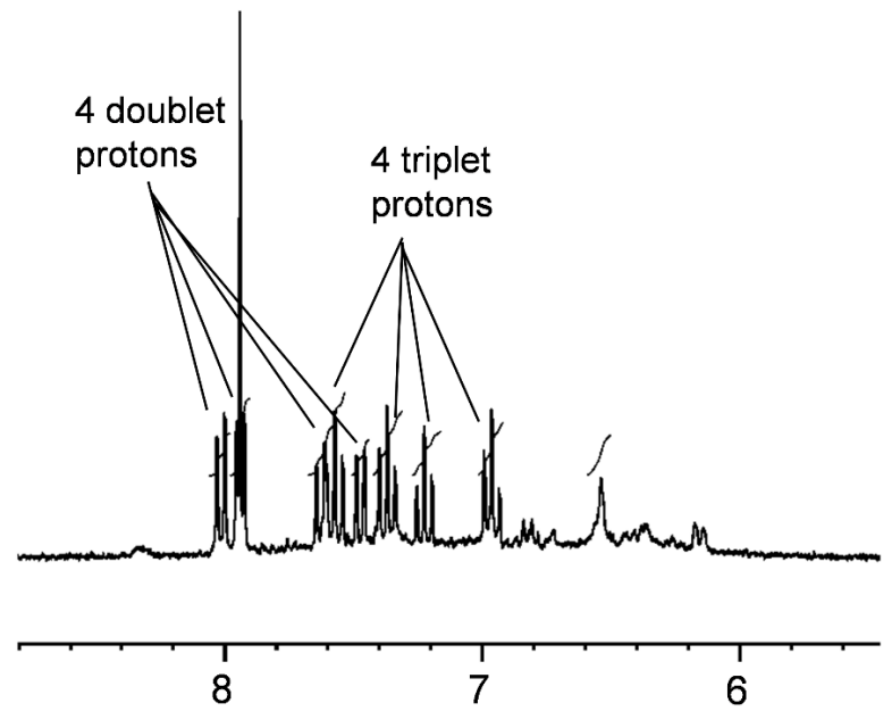

Figure S4 ${ }^{1} \mathrm{H}$ NMR spectrum for product II. Expansion around aromatic protons of the ${ }^{1} \mathrm{H}$ NMR spectrum for product II showed 4 doublet protons and 4 triplet protons, indicating that aromatic substitution did not occur on the aromatic moiety of 1,2-NQ. 


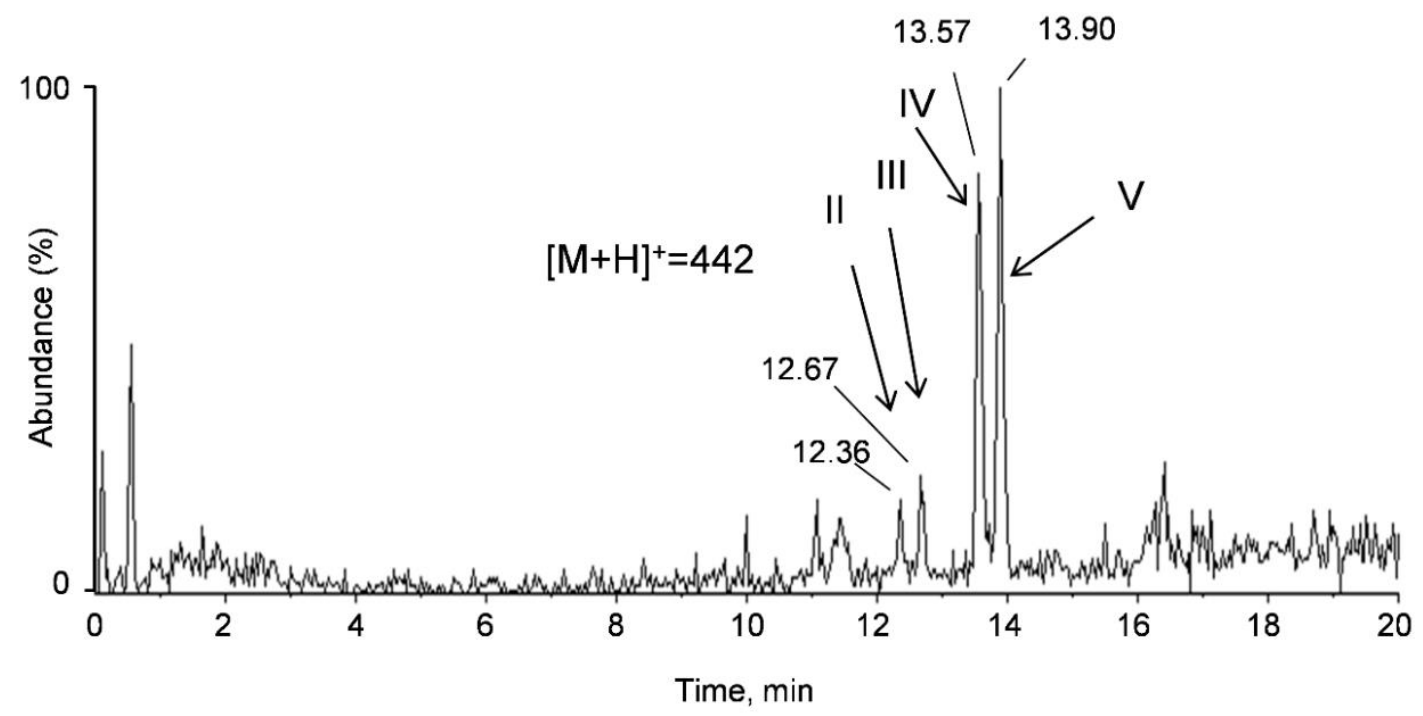

Figure S5 Extracted ion chromatogram from full scan MS analysis of the reaction of isolated product I with dG under $\mathrm{pH} 7.4$ conditions. The peaks which corresponded to $[\mathrm{M}+\mathrm{H}]^{+}=442$ with retention times that were identical to products II through $\mathrm{V}$ were detected.

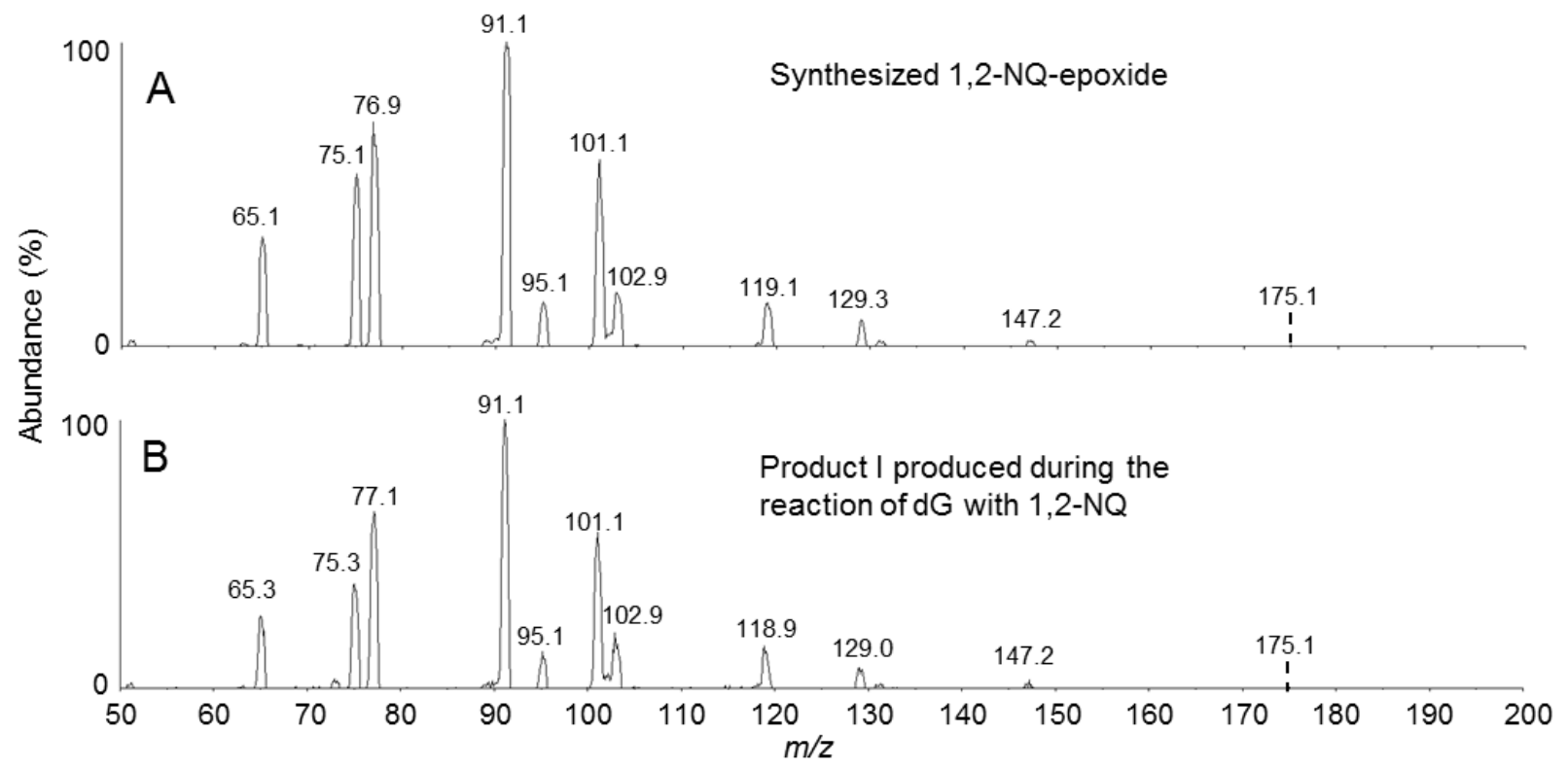

Figure S6 Results of LC/ESI(+)-MS/MS product ion scan analyses of (A) synthesized 1,2-NQepoxide and (B) product I produced during the reaction of 1,2-NQ with dG, Collision energy was $45 \mathrm{~V}$. Results were nearly identical. 


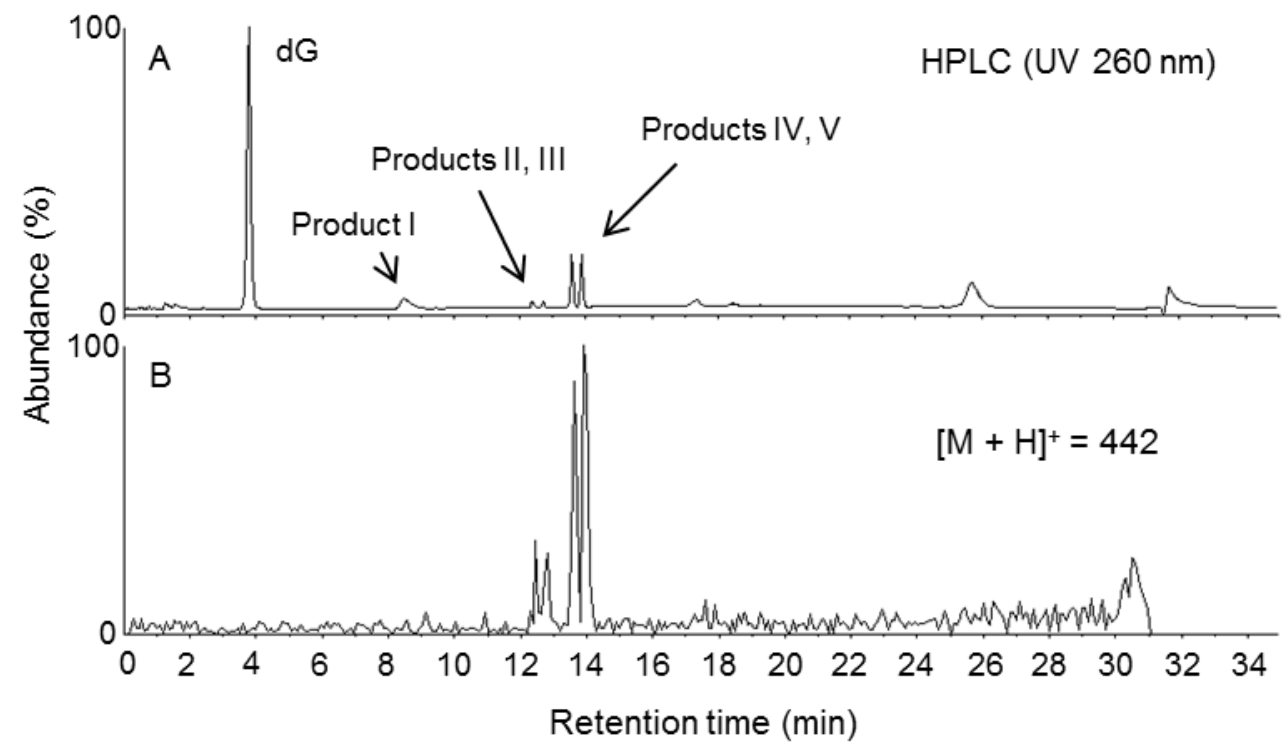

Figure S7 Results of LC/ESI(+)-MS analyses of reaction mixtures of 1,2-NQ-epoxide with dG in phosphate buffer, pH 7.4, after 17 hours (A) UV (260 nm); (B) EIC, [M + H $]^{+}=442$.

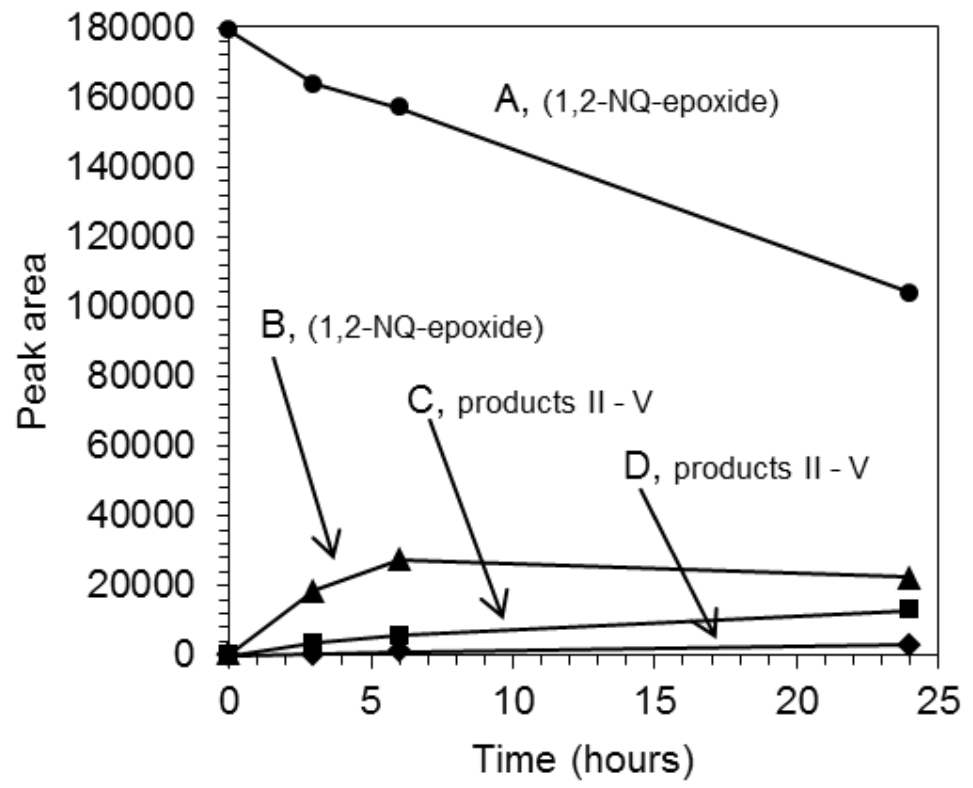

Figure S8 Monitoring of 1,2-NQ-epoxide by peak area measurement (HPLC-UV260nm) when (A) synthesized 1,2-NQ-epoxide (6.2 mM) was incubated directly in phosphate buffer with $\mathrm{dG}$ and (B) when 1,2-NQ (6.2 mM) was incubated in phosphate buffer with dG. Measurement of the total amount of products II through V as the sum of their 4 peak areas when (C) synthesized 1,2-NQ-epoxide was incubated directly in phosphate buffer with $\mathrm{dG}$ and (D) when 1,2-NQ was incubated in phosphate buffer with $\mathrm{dG}$ from the same experiments. 


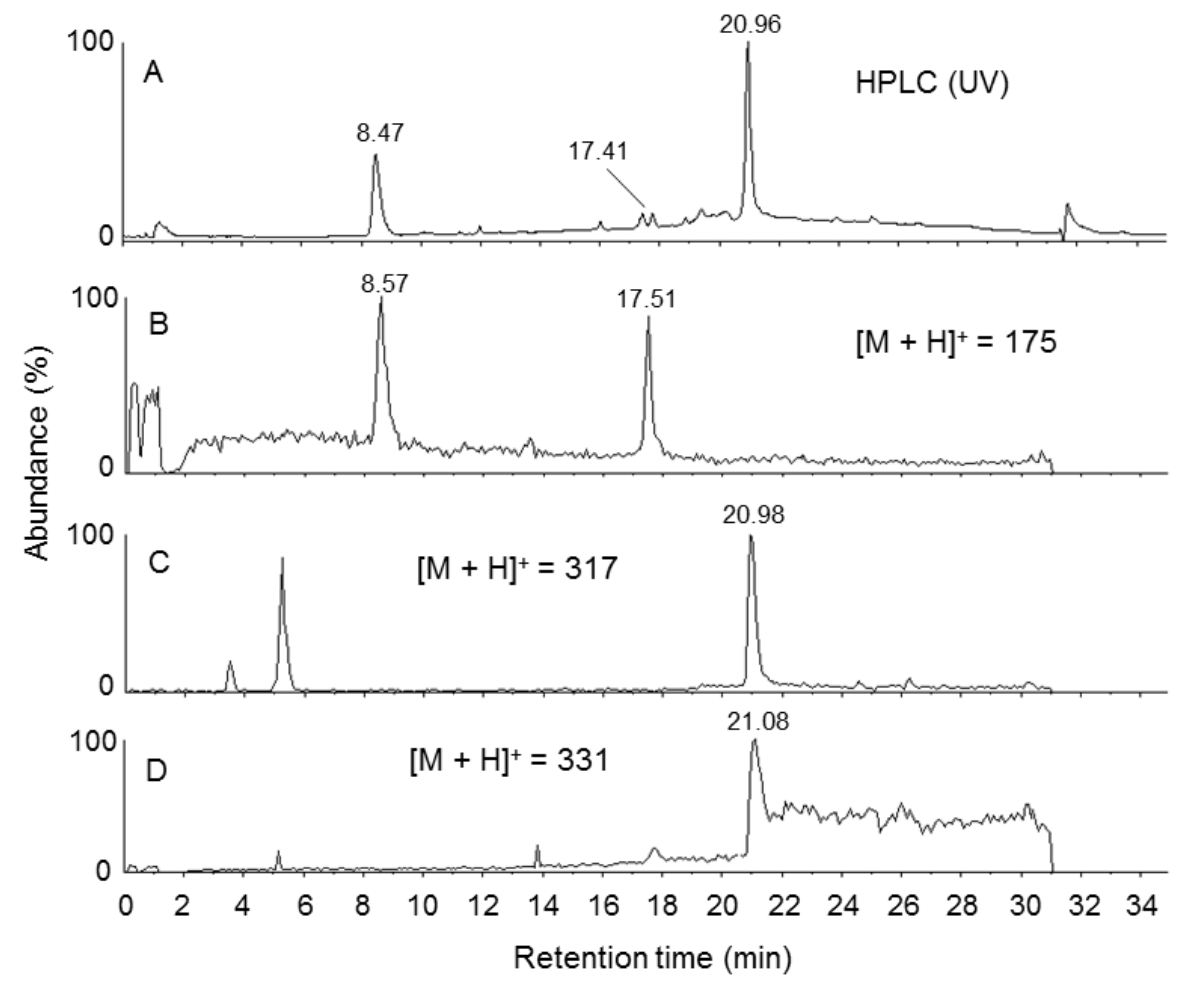

Figure S9 Results of LC/ESI(+)-MS/MS analyses of reaction products formed after addition of 1,2NQ to phosphate buffer, $\mathrm{pH} 7.4$, after 24 hours. (A) UV260nm; (B) extracted ion chromatogram of $[\mathrm{M}+\mathrm{H}]^{+}=175$ (1,2-NQ-epoxide, $8.5 \mathrm{~min}$; lawsone, $\left.17.4 \mathrm{~min}\right)$; (C) extracted ion chromatogram of $[\mathrm{M}+\mathrm{H}]^{+}=317$; (D) extracted ion chromatogram of $[\mathrm{M}+\mathrm{H}]^{+}=331$.
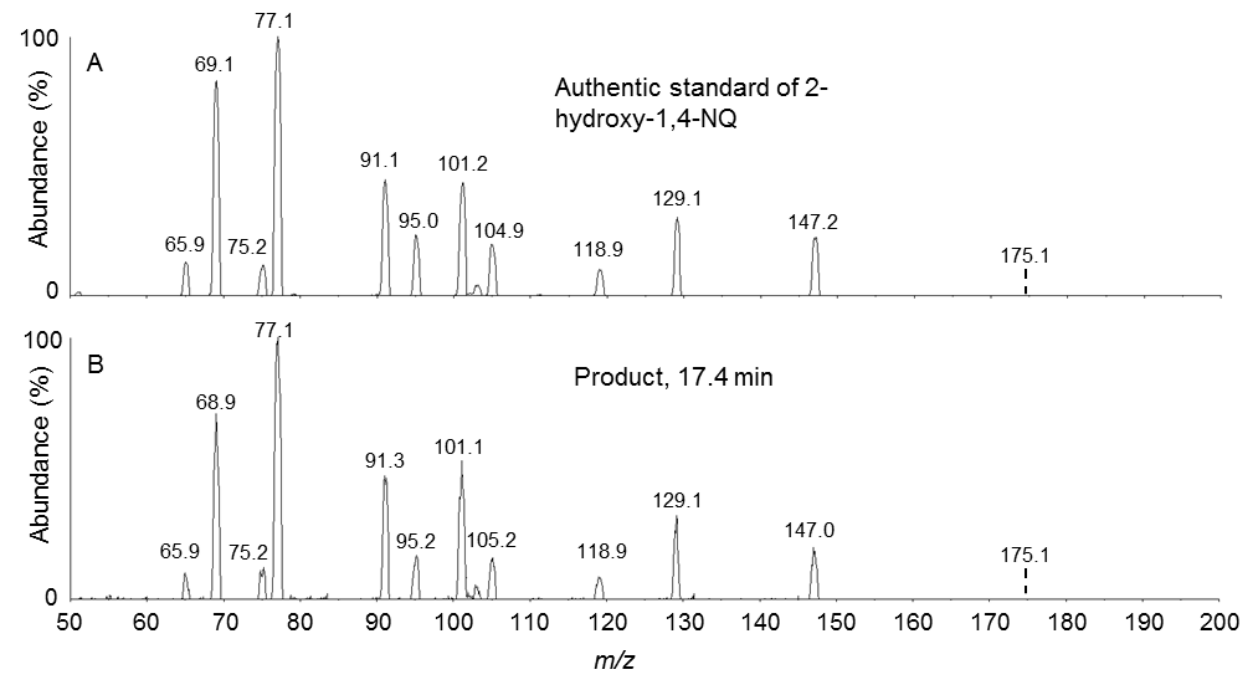

Figure S10 Results of LC/ESI(+)-MS/MS product ion scan analyses of (A) an authentic standard of 2-hydroxy-1,4-naphthoquinone and (B) the product detected at $[\mathrm{M}+\mathrm{H}]^{+}=175$ after 1,2-NQ was added to phosphate buffer, $\mathrm{pH} 7.4$, for 24 hours. Collision energy was $45 \mathrm{~V}$ for each analysis. 


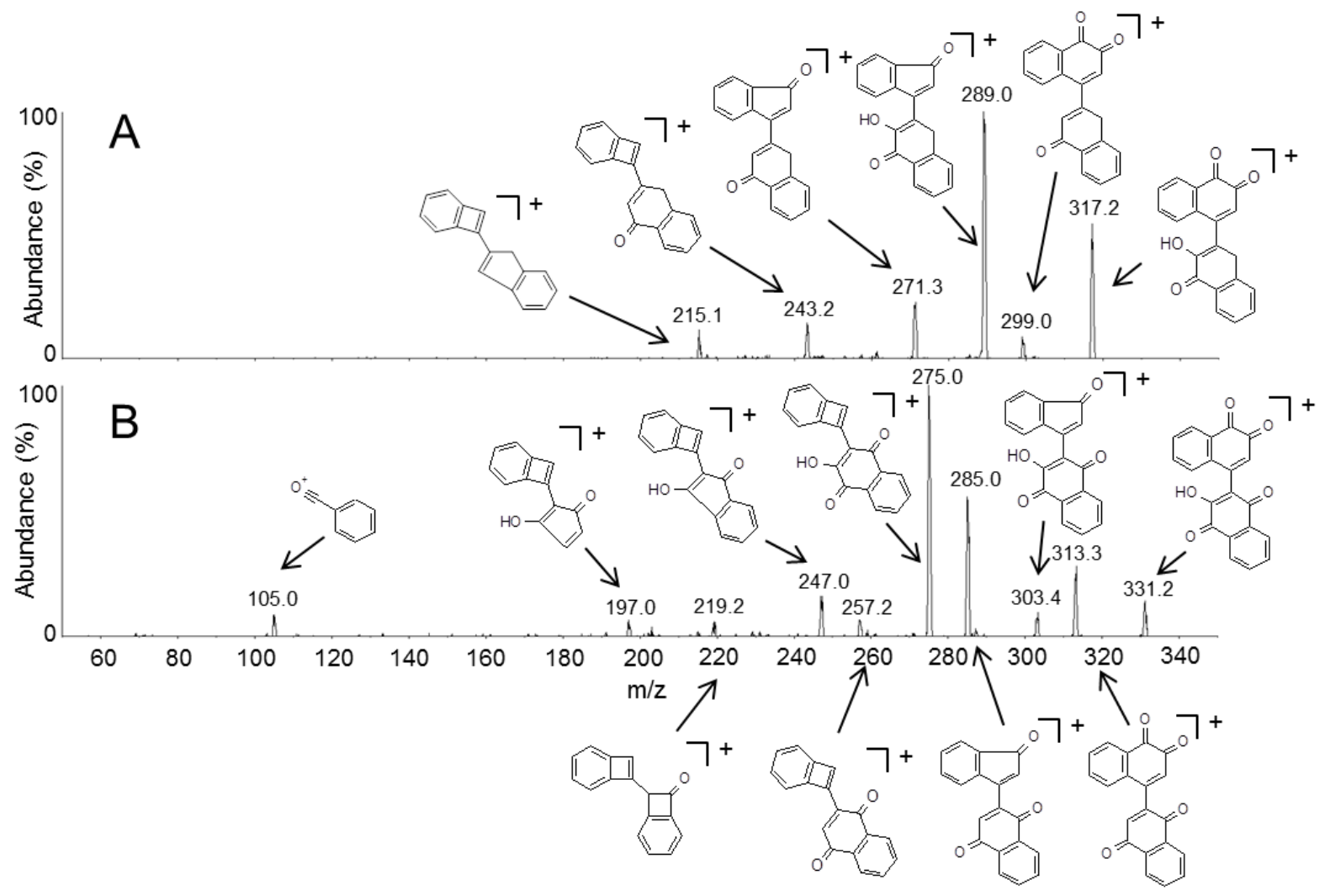

Figure S11 Results of LC/ESI(+)-MS/MS product ion scan analyses of high molar mass products detected during the reaction of 1,2-NQ in phosphate buffer, $\mathrm{pH} 7.4$, for 13 hours; (A) the spectrum of the product that corresponded to $[\mathrm{M}+\mathrm{H}]^{+}=317$; $(\mathrm{B})$ the spectrum of the product that corresponded to $[\mathrm{M}+\mathrm{H}]^{+}=331$. Collision energy was $30 \mathrm{~V}$ for each analysis. 

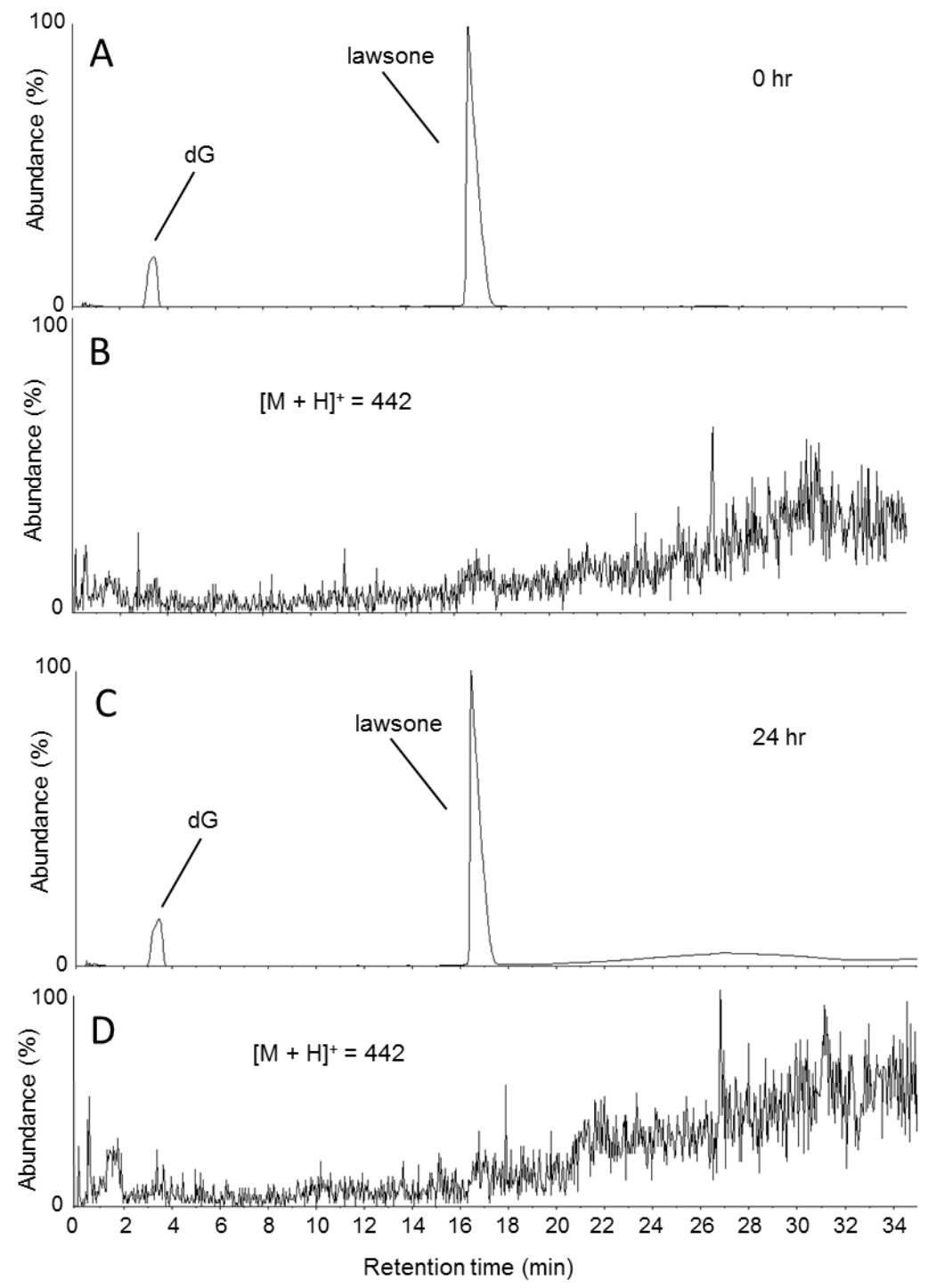

Figure S12 Results of LC/ESI(+)-MS/MS analyses of reaction products from reactions of 2hydroxy-1,4-NQ (lawsone) with dG at 0 hours (A) UV260nm, (B) extracted ion chromatogram of [M $+\mathrm{H}]^{+}=442$; and after 24 hours (C) $\mathrm{UV}_{260 \mathrm{~nm}}$, (D) extracted ion chromatogram of $[\mathrm{M}+\mathrm{H}]^{+}=442$. 

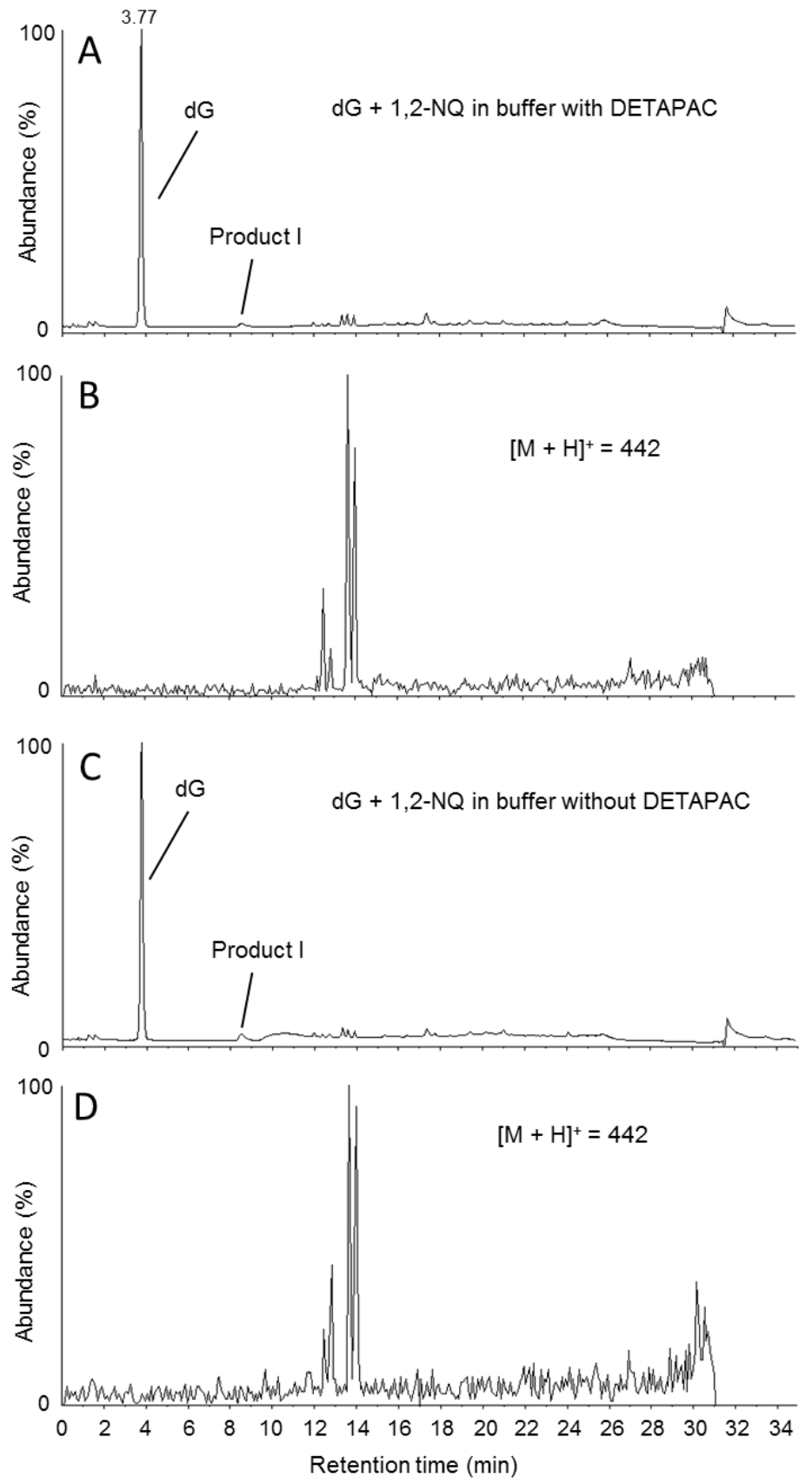

Figure S13 Results of LC/ESI(+)-MS/MS analyses of reaction products from reactions of 1,2-NQ with $\mathrm{dG}$ after 15 hours at $37{ }^{\circ} \mathrm{C}$, with DETAPAC, (A) UV $260 \mathrm{~nm}$, (B) extracted ion chromatogram of $[\mathrm{M}+\mathrm{H}]^{+}=442$; without DETAPAC, (C) UV 260nm, (D) extracted ion chromatogram of $[\mathrm{M}+\mathrm{H}]^{+}=$ 442. 


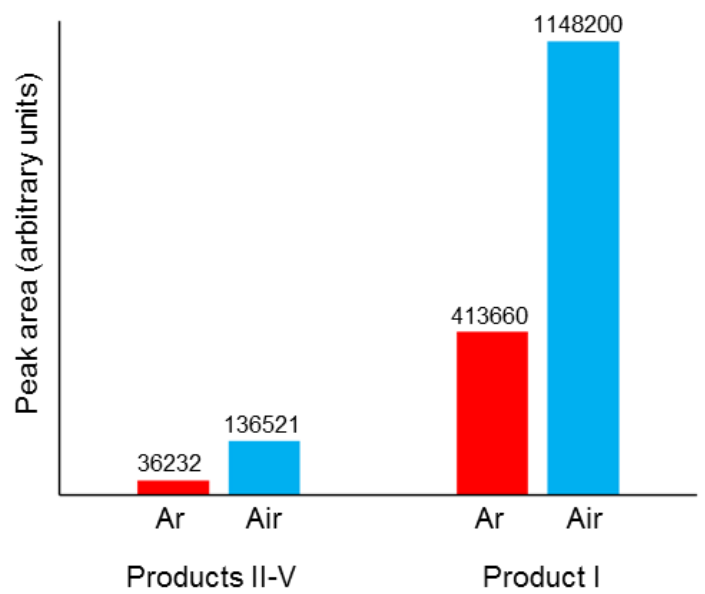

Figure S14 Relative amounts of products II through V (sum of 4 peaks) and product I detected under Ar gas atmosphere conditions and under ambient air conditions when 1,2-NQ was reacted with $\mathrm{dG}$ in phosphate buffer, $\mathrm{pH} 7.4$, for 8 hours in the dark. 